\title{
Morphological and molecular characterisation of Hoplolaimus smokyensis n. sp. (Nematoda: Hoplolaimidae), a lance nematode from Great Smoky Mountains National Park, USA
}

\author{
Xinyuan MA ${ }^{1, *}$, Robert T. RobBins ${ }^{2}$, Ernest C. BernARD ${ }^{3}$, Claudia M. Holguin ${ }^{4}$ and \\ Paula AGUDELO ${ }^{1}$ \\ ${ }^{1}$ Department of Plant and Environmental Sciences, Clemson University, Clemson, SC 29634, USA \\ ${ }^{2}$ Department of Plant Pathology, University of Arkansas, Fayetteville, AR 72701, USA \\ ${ }^{3}$ Department of Entomology and Plant Pathology, University of Tennessee, Knoxville, TN 37996, USA \\ ${ }^{4}$ Corpoica es ahora Agrosavia, Rionegro, 054040, Colombia
}

Received: 25 November 2018; revised: 11 April 2019 Accepted for publication: 11 April 2019; available online: 20 May 2019

\begin{abstract}
Summary - Hoplolaimus smokyensis n. sp. is a new species of lance nematode collected in Great Smoky Mountains National Park, USA. Females of $H$. smokyensis n. sp. have a labial region characterised by six, occasionally five, annules. The basal lip annule is subdivided by about 24 longitudinal striae. The stylet averages $47 \mu \mathrm{m}$ long with robust, tulip-shaped stylet knobs bearing anterior projections. The hemizonid is $c a 4 \mu \mathrm{m}$ anterior to the excretory pore. The lateral field is incompletely areolated and has four continuous incisures from the metacorpus region to the tail region. There are three pharyngeal gland nuclei. Vulval epiptygma are absent. The scutellate phasmids are located one anterior and one posterior to the vulva. The male is shorter than the female and the head region is higher and more rounded than that of the female. The bursa extends to the tail tip and the gubernaculum is large and protrusible and has titillae and a capitulum. Morphologically, H. smokyensis n. sp. is most similar to H. galeatus and H. stephanus, but can be distinguished by differences such as the number of annules and longitudinal striae on the lip region and morphometric values. Hoplolaimus smokyensis $\mathrm{n}$. sp. is also genetically distinct from other species according to comparisons of ribosomal and mitochondrial DNA sequences. Phylogenetic analyses based on ribosomal and mitochondrial gene sequences suggest that $H$. smokyensis $\mathrm{n}$. sp. is a lineage distinct from related Hoplolaimus species.
\end{abstract}

Keywords - Acer sp., Eastern hemlock, Halesia carolina, lance nematode, maple, morphology, morphometrics, new species, phylogeny, plant-parasitic nematode, silverbell, taxonomy, Tsuga canadensis.

During a survey of fauna of Great Smoky Mountains National Park, along the Tennessee-North Carolina border in the south-eastern USA, a Hoplolaimus von Daday, 1905 species was isolated from a mixed forest sample of maple (Acer sp.), Eastern hemlock (Tsuga canadensis (L.) Carrière) and silverbell (Halesia carolina L., 1759). This species was initially distinguished from other reported lance nematodes based on a BLAST (Basic Local Alignment Search Tool) search result of internal transcribed spacer 1 (ITS1) sequences at the NCBI (National Center for Biotechnology Information). Its position was isolated on a phylogenetic tree composed of all available unique ITS1 sequences of Hoplolaimus species from GenBank. A phylogenetic analysis of mitochondrial cytochrome ox-

* Corresponding author, e-mail: xm@g.clemson.edu idase subunit I (COI) sequences supported this result, ensuring that molecular information of this undescribed lance nematode had not yet been reported. Females, males and juveniles were examined for morphological characteristics, morphometrics and phylogenetic relationships. We name the species Hoplolaimus smokyensis $\mathrm{n}$. sp. in reference to the locality where it was first found.

Hoplolaimus smokyensis $\mathrm{n}$. sp. is closest to H. galeatus (Cobb, 1913) Thorne, 1935 and H. stephanus Sher, 1963, but can be distinguished by minor morphological differences, such as the numbers of annules and longitudinal striae in the lip region, morphometric values, and absence of epiptygma. In this study, we applied two genetic markers, mitochondrial $(\mathrm{COI})$ and ribosomal DNA 
(ITS1), to obtain an analysis of higher resolution on taxonomic relationships, which support the delimitation of H. smokyensis n. sp. DNA sequences were aligned with BLAST in GenBank. The highest similarity ( $89 \%$ on both COI and Internal Transcribed Spacer (ITS1) markers) was with $H$. magnistylus Robbins, 1982 sequences. Alignment analyses using MUSCLE (Edgar, 2004) showed unique molecular characteristics possessed by $H$. smokyensis n. sp. Phylogenetic trees generated with MrBayes (Huelsenbeck \& Ronquist, 2001) indicated $H$. smokyensis n. sp. as a distinct clade.

\section{Materials and methods}

\section{NEMATODE ISOLATION}

Female, male and juvenile specimens were sampled from Great Smoky Mountains National Park in July 2006. Nematodes were extracted from soil with a combination of sieving-decanting and sucrose centrifugal-flotation (Jenkins, 1964). Specimens were killed and fixed, processed to glycerin and permanently mounted on slides as described by Ye \& Robbins (2003).

\section{MORPHOLOGICAL OBSERVATION AND MICROGRAPHY}

Permanently mounted specimens were examined and imaged. Some live specimens were imaged as well. Most images were produced with a 14-megapixel Q-camera on an Olympus BX-63 differential interference-contrast microscope system. Measurements were made on a Nikon Optiphot II compound microscope with the aid of a drawing tube or ocular micrometer. Mean annule width was calculated by measuring a series of ten annules at mid-body.

\section{MOLECULAR PROFILES AND PHYLOGENY}

DNA was extracted from individual nematodes using Sigma Extract-N-Amp kit (XNAT2) (Sigma). The manufacturer's protocol was modified by reducing volumes to one eighth of the recommended amount (Ma et al., 2011). The ITS1 was amplified with primers Hoc-1f (5'-AACCTGCTGCTGGATCATTA-3') and LSUD3r (5'TATGCTTAAGTTCAGCGGGT-3') following Bae et al. (2008, 2009); and a portion of cytochrome c oxidase subunit I (COI) sequence was amplified with primers JB3 (5'-TTTTTTGGGCATCCTGAGGTTTAT- $\left.3^{\prime}\right)$ and JB5 (5'-AGCACCTAAACTTAAAACATAATGAAA-3') (Derycke et al., 2005). For COI, the initial denaturation was set at $95^{\circ} \mathrm{C}$ for $3 \mathrm{~min}$, followed by 33 cycles of $95^{\circ} \mathrm{C}$ for $45 \mathrm{~s}, 50^{\circ} \mathrm{C}$ for $1 \mathrm{~min} 15 \mathrm{~s}, 72^{\circ} \mathrm{C}$ for $2 \mathrm{~min}$ and final extension at $72^{\circ} \mathrm{C}$ for $10 \mathrm{~min}$ (Holguin et al., 2015a). The amplified products were loaded onto a $1.5 \%$ agarose gel and visualised with GelRed ${ }^{\mathrm{TM}}$ (Biotium). PCR products for both regions were purified using magnetic beads and sequenced in both directions with the ABI 3730 capillary sequencer (Applied Biosystems) in the DNA Laboratory (School of Life Sciences) at Arizona State University. Sequencing results were edited and assembled in Sequencher 5.1 (Genes Code). Consensus DNA sequences were searched in GenBank using BLAST, then aligned with MUSCLE (Edgar, 2004).

A best-fit model of nucleotide substitution was selected using the GTR + I + G model with the Akaike Information Criterion (AIC) among 56 different models using ModelTest v 3.7 (Posada \& Crandall, 1998). Bayesian inference was implemented for each gene separately using the MrBayes 3.1.2 program (Huelsenbeck \& Ronquist, 2001) running the chain for $1 \times 10^{7}$ generations with the Markov chain Monte Carlo (MCMC) method, a sample frequency of 100 and burn-in value of 2500 . We estimated the posterior probabilities of the phylogenetic trees (Larget \& Simon, 1999) using the 50\% majority rule. The phylogenetic trees were viewed on phylo.io (Robinson et al., 2016) and iTOL (Interactive tree of life v3) (Letunic \& Bork, 2016).

\section{Results}

\section{Hoplolaimus smokyensis* n. sp.} (Figs 1-4)

\section{MEASUREMENTS}

See Table 1.

\section{DESCRIPTION}

\section{Female}

Female body generally cylindrical, vermiform, tapering slightly at each end. Head set off, with massive cephalic framework, usually bearing six lip annules and the oral disc, but sometimes with five annules (six individuals out of 30 specimens), basal annule tessellated, divided into $c a$ 20 equal blocks (Fig. 1A, B). Oral disc surrounded by a lip annule separated into six sections: two subdorsal, two

\footnotetext{
* The specific epithet refers to the locality where the species was first found.
} 
Table 1. Morphometrics of Hoplolaimus smokyensis n. sp. All measurements are in $\mu \mathrm{m}$ and in the form: mean \pm s.d. (range).

\begin{tabular}{|c|c|c|c|}
\hline \multirow[t]{2}{*}{ Character } & \multicolumn{2}{|c|}{ Female } & \multirow{2}{*}{$\begin{array}{c}\text { Male } \\
\text { Paratypes }\end{array}$} \\
\hline & Holotype & Paratypes & \\
\hline $\mathrm{n}$ & - & 30 & 17 \\
\hline $\mathrm{L}$ & 1409 & $1335 \pm 174(997-1870)$ & $1096 \pm 87(972-1261)$ \\
\hline $\mathrm{a}$ & 34.7 & $30.1 \pm 3.3(23.5-36.9)$ & $30.5 \pm 2.3(26.1-34.5)$ \\
\hline b & 9.9 & $9.8 \pm 1.6(7.1-14.9)$ & $8.1 \pm 0.7(7.1-9.3)$ \\
\hline$b^{\prime}$ & 7.3 & $6.8 \pm 0.9(4.9-8.9)$ & $5.8 \pm 0.5(5.2-6.7)$ \\
\hline $\mathrm{c}$ & 115.7 & $114 \pm 15.8(91.3-154)$ & $36.8 \pm 3.7(28.9-42.3)$ \\
\hline$c^{\prime}$ & 0.7 & $0.7 \pm 0.1(0.5-1.0)$ & $1.5 \pm 0.2(1.3-1.9)$ \\
\hline V & 54.4 & $56.5 \pm 2.6(49.7-62.1)$ & - \\
\hline Max. body diam. & 41 & $44.4 \pm 4.1(34.5-52.8)$ & $36.1 \pm 3.4(30.5-42.6)$ \\
\hline Lip annulus & 6 & $5.8 \pm 0.4(5-6)$ & $5.8 \pm 0.4(5-6)$ \\
\hline Lip height & 8 & $8.1 \pm 0.3(7.1-9.1)$ & $8.1 \pm 0.2(7.1-8.7)$ \\
\hline Lip diam. & 16 & $15.8 \pm 1.0(14.2-18.3)$ & $13.9 \pm 0.6(12.2-14.2)$ \\
\hline Conus & 24 & $25.8 \pm 1.6(22.3-28.4)$ & $23.8 \pm 1.5(22.3-26.4)$ \\
\hline Stylet length & 47 & $47.9 \pm 1.9(44.7-50.8)$ & $43.4 \pm 2.1(40.6-48.7)$ \\
\hline Pharynx & 142 & $138 \pm 16.7(79-183)$ & $136 \pm 6.4(126-152)$ \\
\hline Anterior end to pharyngeal gland tip & 193 & $199 \pm 11.2(168-223)$ & $189 \pm 10.7(173-207)$ \\
\hline Tail length & 26 & $24.9 \pm 4.0(20.3-34.5)$ & $30.0 \pm 3.4(24.4-36.5)$ \\
\hline Anal body diam. & 37 & $35.5 \pm 3.1(28.4-40.6)$ & $20.2 \pm 1.3(18.3-22.3)$ \\
\hline Hemizonid from anterior end & 162 & $157 \pm 14.2(140-207)$ & $150 \pm 8.8(132-166)$ \\
\hline Excretory pore from anterior end & 166 & $164 \pm 14.7(144-217)$ & $156 \pm 8.6(136-173)$ \\
\hline Dorsal pharyngeal gland orifice & 12 & $11.7 \pm 0.9(10.2-12.2)$ & $7.0 \pm 1.0(6.1-8.1)$ \\
\hline Vulva from anterior end & 766 & $753 \pm 100(602-1112)$ & - \\
\hline Spicule length & - & - & $41.1 \pm 2.5(36.5-46.7)$ \\
\hline Gubernaculum & - & - & $10.5 \pm 0.6(10-12)$ \\
\hline
\end{tabular}

subventral, and two reduced lateral sectors. Stylet long and robust, basal knobs tulip-shaped (Fig. 1C-E). Dorsal pharyngeal gland orifice $\mathrm{ca} 12 \mu \mathrm{m}$ from base of stylet knobs. Pharyngeal glands with three nuclei, one nucleus in the dorsal gland. Pharyngo-intestinal junction at 6-12\% of body length from anterior end. Pharyngeal lobe terminus at $12-16 \%$ of body length from anterior end. Excretory pore prominent (Fig. 1F), at 10-15.5\% of body length from anterior end. Hemizonid large, spanning about two annules, just anterior to excretory pore (Fig. 1G). Lateral field with four incisures, incompletely areolated (Fig. 2A), narrowing to two incisures at level of metacorpus, ending near level of stylet base; posteriorly, lateral field abruptly ending by joining of the outer incisures at level of anus (Fig. 2E, F). Phasmids large, scutelliform, conspicuous, variable in position, right phasmid located anterior to vulva, left one located posterior, anterior one at $20-40 \%$ and posterior one at $60-90 \%$ of body length from anterior end. Vulva prominent, located near mid-body, with deep transverse slit, epiptygma absent (Fig. 2B). Ovaries two, outstretched. Spermatheca round to oval, usually with many sperm (Fig. 2C). Cuticular annulation at mid-body distinct, annule width $2 \mu \mathrm{m}$, subcuticular annulation distinct, about half as wide as outer cuticular annules. Tail hemispherical to conoid-hemispherical (Fig. 2E, F).

Male

Body shape similar to female, cylindroid, vermiform. Body length generally shorter than female. Head set off, labial region exhibiting sexual dimorphism, higher and rounder than females when viewed laterally (Fig. 4A, B). Head region usually bearing six lip annules and the oral disc, occasionally five annules (four individuals out of 17 specimens). Stylet knobs tulip-shaped. Excretory pore at $12-14 \%$ of body length from anterior end, 2-3 annules posterior to hemizonid. Cuticular annules at mid-body $c a$ $2 \mu \mathrm{m}$ wide. Lateral field areolated, with four incisures. Testis one, outstretched anteriorly. Spicules and gubernaculum long and prominent, bursa large and conspicuous, extending to tail tip. Gubernaculum large, protrusible, with prominent capitulum and titillae (Figs 3B; 4D). 

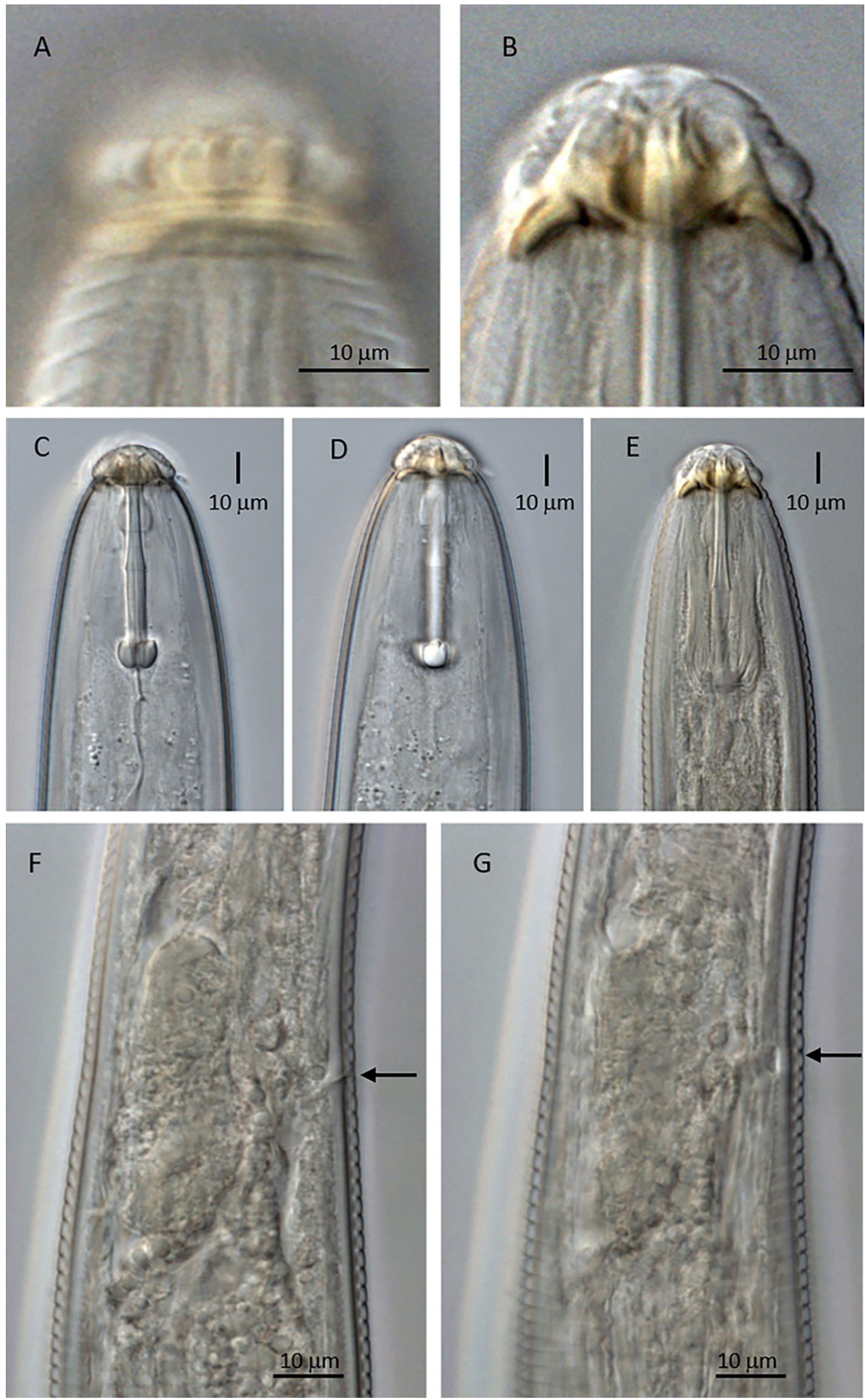

Fig. 1. Micrographs of Hoplolaimus smokyensis n. sp. females from Great Smoky Mountains National Park. A, B: Head of the same female specimen showing lip annules and longitudinal striae; C-E: Stylet view with different focusing; F, G: Pharyngeal region of the same female specimen showing excretory pore $(\mathrm{F})$ and hemizonid $(\mathrm{G})$ indicated by arrows. 

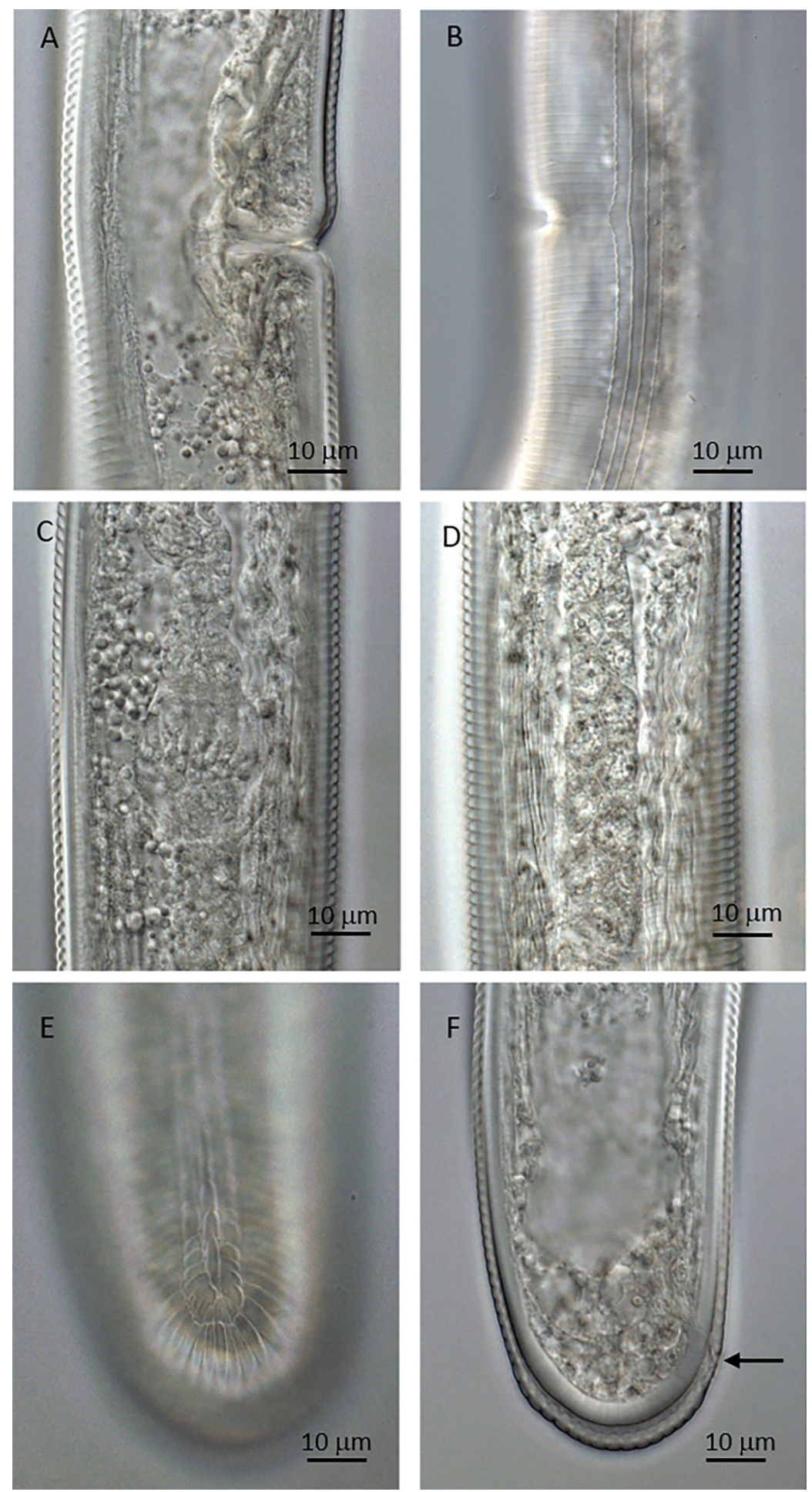

Fig. 2. Micrographs of Hoplolaimus smokyensis n. sp. females from Great Smoky Mountains National Park. A: Vulval region with no epiptygma; B: Incomplete areolation in lateral field; C: Ovary with sperm; D: Oocytes; E, F: Tail of same female specimen showing lateral field incisures, areolation and anus (arrow). 

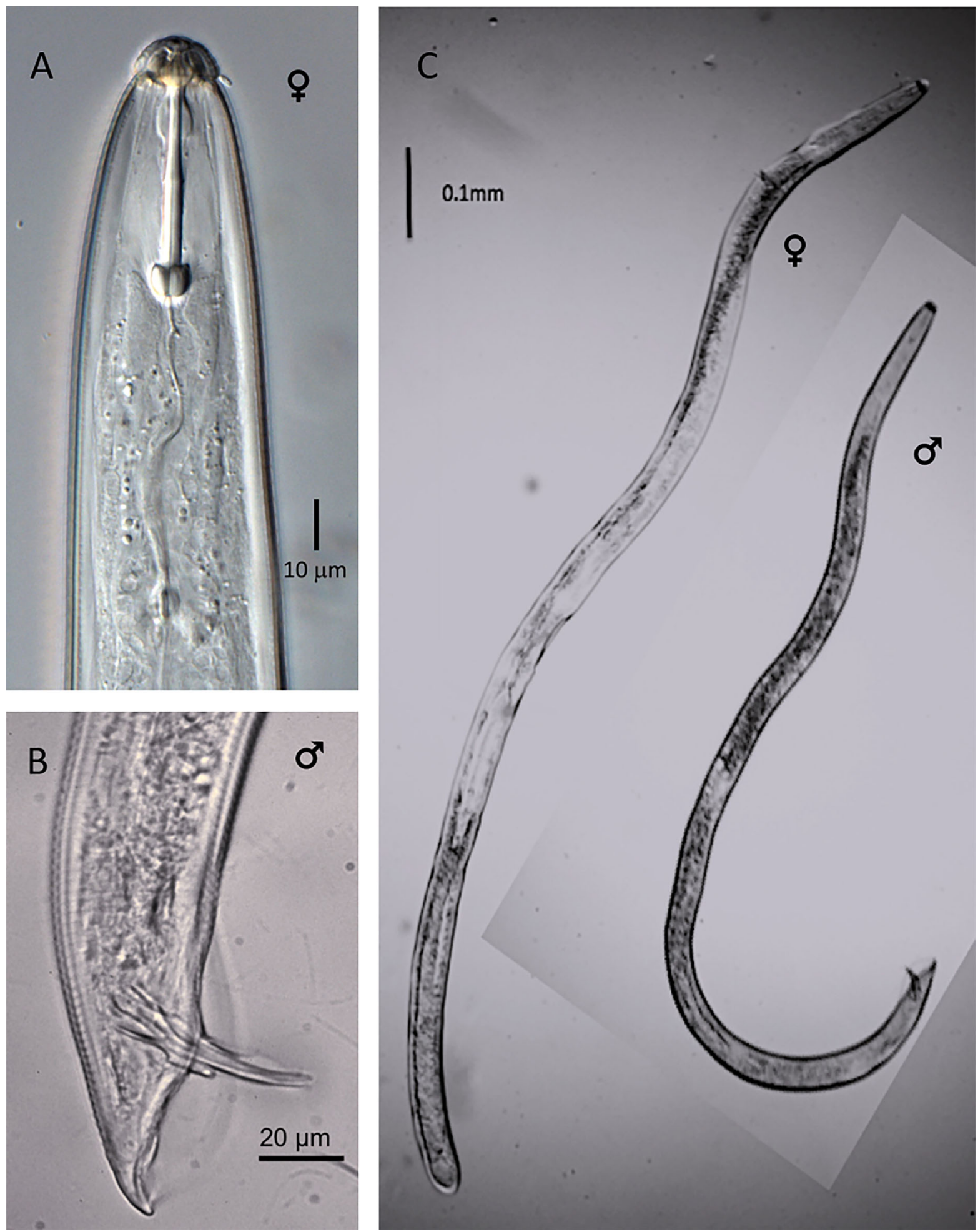

Fig. 3. Micrographs of Hoplolaimus smokyensis n. sp. from Great Smoky Mountains National Park. A: Female head with stylet, dorsal pharyngeal gland orifice and median bulb; B: Male tail; C: Habitus of male and female. 

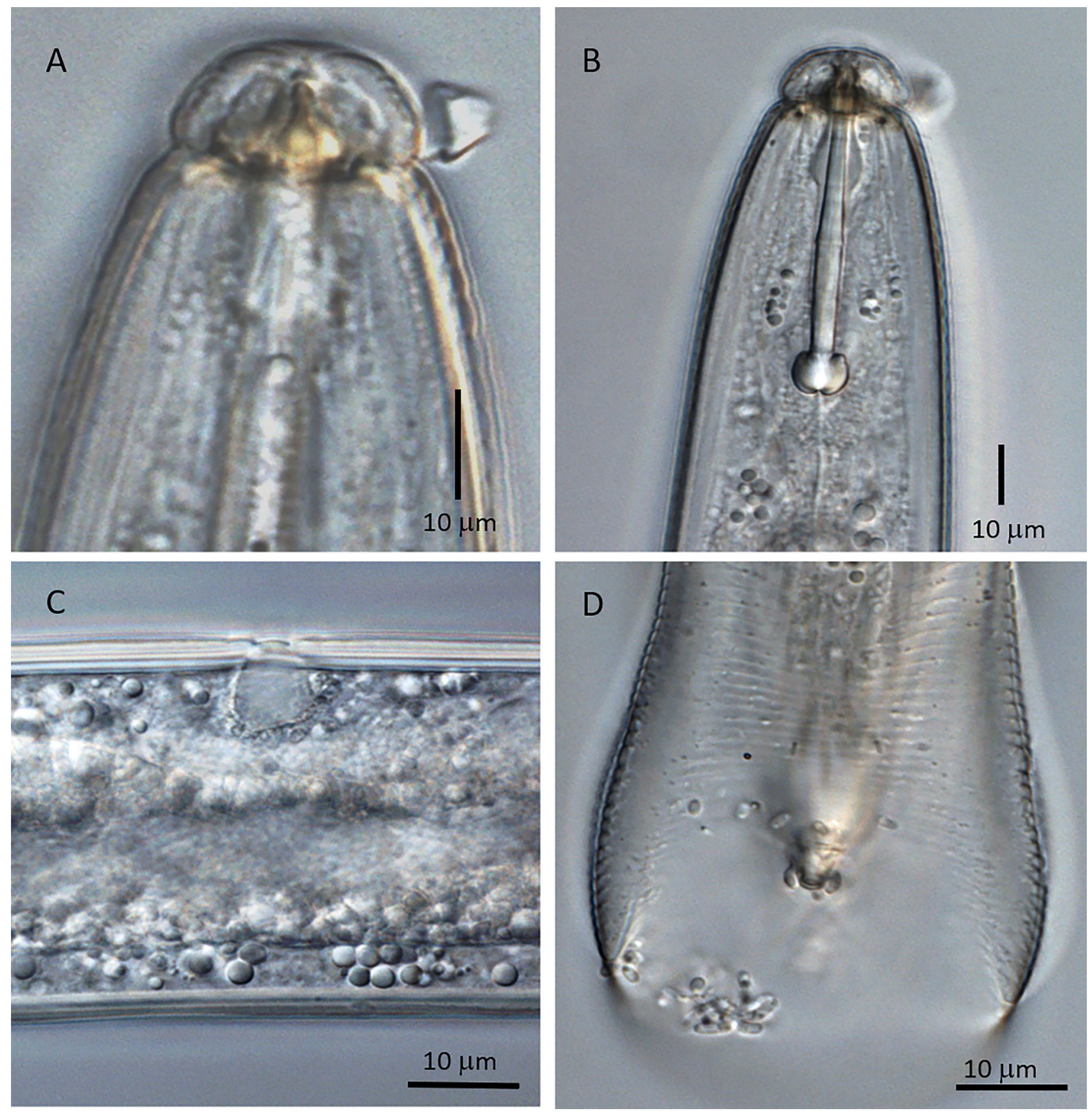

Fig. 4. Micrographs of Hoplolaimus smokyensis n. sp. males from Great Smoky Mountains National Park. A, B: Head of same male specimen showing head lip region (A) and stylet (B); C: Ventral view of an anterior phasmid; D: Ventral view of male tail.

TYPE LOCALITY

All specimens were obtained from Great Smoky Mountains National Park, Sevier County, TN, USA, Laurel
Falls Trail, $35^{\circ} 40.874^{\prime} \mathrm{N}, 83^{\circ} 36.149^{\prime} \mathrm{W}$, elevation $1008 \mathrm{~m}$ a.s.l., in a mixed maple (Acer sp.), Eastern hemlock (Tsuga canadensis) and silverbell (Halesia carolina) forest. 


\section{TYPE MATERIAL}

Holotype female (T-702t) and five paratype slides (T-6864p to T-6868p containing seven females and seven males) deposited in the Nematology Laboratory Collection, USDA, ARS, Beltsville, MD, USA. Five other paratype slides (28506-28510), including ten females, seven males and five juveniles, deposited in the Department of Nematology, University of California, Riverside, CA, USA.

\section{DIAGNOSIS AND RELATIONSHIPS}

Females of $H$. smokyensis n. sp. have a labial region characterised by six, occasionally five, annules. The basal lip annule is subdivided with about 24 longitudinal striae. The stylet averages $47 \mu \mathrm{m}$ long with robust, tulipshaped stylet knobs bearing anterior projections. The hemizonid is ca $4 \mu \mathrm{m}$ anterior to the excretory pore. The lateral field is incompletely areolated and has four continuous incisures from the metacorpus region to the tail region. There are three pharyngeal gland nuclei. Vulval epiptygma are absent. The scutellate phasmids are located one anterior and one posterior to the vulva. The male is shorter than the female. In lateral view the male head region is higher and more rounded than that of the female. The bursa extends to the tail tip and the gubernaculum is large and protrusible and has titillae and a capitulum.

Hoplolaimus smokyensis $\mathrm{n}$. sp. keys to couplet 8 in Handoo \& Golden (1992) but does not fit either species. It resembles $H$. galeatus in sometimes having five labial annules but has 20-24 longitudinal incisures on the basal lip annule vs 32-36 in $H$. galeatus. The number of longitudinal incisures is similar to that of $H$. stephanus but the latter has only four labial annules rather than five or six. Hoplolaimus smokyensis n. sp. differs from other species with four lateral incisures as follows: body length longer than that of $H$. aorolaimoides Siddiqi, $1972(\mathrm{~L}=$ 1.25 (1.1-1.4) vs 0.85 (0.8-0.92) mm); phasmids located as one anterior and one posterior to the vulva, differing from those in H. californicus Sher, 1963 or H. igualaensis Cid Del Prado Vera, 1994, (both posterior to vulva); 5-6 labial annules vs 4 in H. clarissimus Fortuner, 1974, 3 or 4 in H. tylenchiformis von Daday, 1905 or 3 in H. sacchari (Shamsi, 1979) Luc, 1981; juvenile tail not pointed as in $H$. concaudajuvencus Golden \& Minton, 1970; and stylet shorter than in H. magnistylus (47 (41-51) vs 55.7 (52-61) $\mu \mathrm{m})$.

\section{MOLECULAR PROFILES AND PHYLOGENY}

Molecular sequences obtained in this study are deposited in the GenBank database with accession num-

Table 2. Origin and GenBank accession numbers of Hoplolaimus species ITS1 gene sequences used in this study.

\begin{tabular}{|c|c|c|c|}
\hline Species & Origin & Host & Accession number \\
\hline H. columbus & Pierce County, GA & Soybean, Glycine max & KP835333 \\
\hline H. columbus & Barnwell County, SC & Sorghum, Sorghum bicolor & KP835315 \\
\hline H. concaudajuvencus & Dallas County, TX & Bentgrass, Agrostis sp. & KP303685 \\
\hline H. concaudajuvencus & Dallas County, TX & Bentgrass, Agrostis sp. & KP303686 \\
\hline H. galeatus & Baldwin County, AL & Bermuda, Cynodon dactylon & KP303596 \\
\hline H. galeatus & St Johns, FL & St Augustine, Stenotaphrum secundatum & KP303607 \\
\hline H. magnistylus & Weakley County, TN & Corn, Zea mays & KP303681 \\
\hline H. magnistylus & Massac County, IL & Soybean, G. $\max$ & KP303634 \\
\hline H. seinhorsti & Alachua County, FL & Peanut, Arachis hypogaea & EU515327 \\
\hline H. seinhorsti & Fujian, China & Turfgrass & KF486504 \\
\hline Hoplolaimus sp. 1 & Smoky Mountains, TN & - & EU515329 \\
\hline Hoplolaimus sp. 2 & University of Illinois, IL & - & EU515330 \\
\hline Hoplolaimus sp. 2 & Manhattan, KS & Corn, Zea mays & EU515331 \\
\hline Hoplolaimus sp. 3 & Clemson, SC & Birch tree, Betula sp. & EU515332 \\
\hline Hoplolaimus sp. 3 & Limestone County, IA & Cotton, Gossypium sp. & EU515333 \\
\hline H. stephanus & Sargent County, ND & Soybean, G. $\max$ & KX347888 \\
\hline H. stephanus & Riley County, KS & Bentgrass, Agrostis sp. & KP303646 \\
\hline H. stephanus & Warren County, $\mathrm{OH}$ & Bentgrass, Agrostis sp. & KP303664 \\
\hline H. smokyensis $\mathrm{n} . \mathrm{sp}$. & Sevier County, TN & Maple, Acer sp. & KP303683 \\
\hline H. smokyensis n. sp. & Sevier County, TN & Maple, Acer sp. & KP303684 \\
\hline
\end{tabular}


Table 3. Origin and GenBank accession numbers of Hoplolaimus species COI gene sequences used in this study.

\begin{tabular}{llll}
\hline Species & Origin & Host & Accession number \\
\hline H. columbus & Barnwell County, SC & Sorghum, Sorghum bicolor & KP864583 \\
H. columbus & Pierce County, GA & Soybean, Glycine max & KP864611 \\
H. concaudajuvencus & Dallas County, TX & Bentgrass, Agrostis sp. & KP230667 \\
H. concaudajuvencus & Dallas County, TX & Bentgrass, Agrostis sp. & KP230668 \\
H. galeatus & St Johns, FL & St Augustine, Stenotaphrum secundatum & KP230564 \\
H. galeatus & Baldwin County, SC & Bermuda, Cynodon dactylon & KP230554 \\
H. magnistylus & Massac County, IL & Soybean, G. max & KP230588 \\
H. magnistylus & Weakley County, TN & Corn, Zea mays & KP230657 \\
H. stephanus & Riley County, KS & Bentgrass, Agrostis sp. & KP230593 \\
H. stephanus & Warren County, OH & Bentgrass, Agrostis sp. & KP230626 \\
H. smokyensis n. sp. & Sevier County, TN & Maple, Acer sp. & KP230658 \\
H. smokyensis n. $\mathrm{sp}$. & Sevier County, TN & Maple, Acer sp. & KP230659 \\
\hline
\end{tabular}

H_smokyensis_n.sp.
H_stephanus
H_galeatus
H_magnistylus
H_concaudajuvencus
H_smokyensis_n.sp.
H_stephanus
H_galeatus
H_magnistylus
H_concaudajuvencus
H_smokyensis_n.sp.
H_stephanus
H_galeatus
H_magnistylus
H_concaudajuvencus
H_smokyensis_n.sp.
H_stephanus
H_smokyensis_n.sp.
H_galeatuaghisteatus
H_magnistylus
H_concaudajuvencus

CGATTGGTAATGTGTTGA-CGAGGACAAGAGTCCAAGCAAACTGACGACCGGGTTAGGCG CGATTACAATTGTGTGGA-CGATGCGAAGAGACCAAGCAAACTGGCAGCC-GGTTAGGCG CGATTGTCAATGTGTGAA-CGAGGAGAAGAGTCCAAGCAATCTAATAACC-GGCTAGGTA TTATTACTAATGTGTGGAGCATGGCGAAGTGTCCAAGCAATCTGACGACC-AGTTAGGCG TTATTACTAATGTGTGGAGCATGGCGAAGTGTCCAAGCAATCTGACGACC-AGTTAGGCG *** * ****** ** * *************** *** *****

TTGGTGAGTTGTCCTGTGTGCTGAATGACTTGCCCTTGGGGCACCTAACGGCTGCACTGG TTAGTAAGCTGTCCTGCGTGCTAAATGACC-GCCCTCGAGGCAACCAACGGCTACGCTGG TTGGTGAACTGTCCTG--TGCTGAATAACTTGCCCTCGGGGCGCATAACGGCTGCGCTGG TTGGAAAGCTGTCCTGTTTGTTGGATGACTAACCCTCGGGGCACCTAACGGCTGCGCTGG TTGGAAAGCTGTCCTGTTTGTTGGATGACTAACCCTCGGGGCACCTAACGGCTGCGCTGG *** * * *********** ***** ********* $* * * * * * * * * * * *$

TGTCTGAGCGTTGTTGAGCAGTTGTTGTGCACATGAGGTGCGGAGATGTGAGCGGAACAT TGTCTGTGCGTTGTTGAGCAGTTGTTGTGCACATGAGACGAGGAGTTGCGAGCGGAACAC CGTCTGTGCGTTGTTGAGCAGTTGTTGTGCGCATGGAACGTGGAGATATAATCGGAGCAC TGTCTGTGCGTTGTTGAGCAGTTGTTGTGCACATGAGACGCGGAGATGT-AGCGGAACAC TGTCTGTGCGTTGTTGAGCAGTTGTTGTGCACATGAGACGCGGAGATGT-AGCGGAACAC ***** ************************** **** $* * * * * * \quad * * * * * * *$

GCT-GCATGGACATTTGAGCCAACTTGGCTGTCCATGTCTTATACGCCATAACTAGGGTG ACTGGCATGGATTTTTGTTCTAACTGGACTTTCCATGTCTTACATGCCGTAAACAAGGTG TCCGGCATGGACCTGTAGGCCAACTGGGTCGTCCATGTCTTACATGCTGTAATTGTGGTG GCTGGCATGGACCTTTAGGCAACTTTGGCCGTCCATGTCTTACATGCTGTAATTAGGGTG GCTGGCATGGACCTTTAGGCAACTTTGGCCGTCCATGTCTTACATGCTGTAATTAGGGTG

$* * * * * * * * * * * * * * * \quad * * * * * * * * * * * * * * \quad * * * \quad * * * *$

TGT-ACCTGCCGCTCTCTGACGATATGTGAACTACGTCCGTGGCTGCGATGAGATAACGC TGC-TTTTGCCGTTTTCTGACGACATGTGTACTACGTCCGTGGCTGCGATGAGATGACGC TGTTTCCCGCTATTCTCTGACGACATGTGTACTACGTCCGTGGCTGTGATGAGACGACGC TGTCGCCCGCCGCTCTCTGACGACGTGTGCACTACGTCCGTGGCTGCGATGAGATGACGC TGTCGCCCGCCGCTCTCTGATGACGTGTGCACTACGTCCGTGGCTGCGATGAGATGACGC ** $\quad * * \quad * * * * * * * * \quad * * * * * * * * * * * * * * * * * * * * * * * * * * * \quad * * * *$

GGTAGGACCCGTGCACGAGTTGCGCGTGGTTTAAGACTCGATGAGCTCAAAGATTAGAGC GGTAGGGCCCGTGCACGAGTTGCGCGTGGTTTAAGACTCGATGAGCTCAAAGGTAAGAGC GGTAGGACCCGTGCACGAGTTGCGCGTGGTTTAAGACTCGATGAGCTCAAAGTTAAGAGC GGTAGGACCCGTGCACGAGTTGCGCGTGGTTTAAGACTCGATGAGCTCAAAGTTAAGAGC GGTAGGACCCGTGCACGAGTTGCGCGTGGTTTAAGACTCGATGAGCTCAAAGTTAAGAGC ******* $* * * * * * * * * * * * * * * * * * * * * * * * * * * * * * * * * * * * * * * * * * * * * * * * \quad * \quad * * * * *$

CGCCAGCATCCCTTTTTT-AATTAAACTTTTTTGTGCACC---GCATGGTGCTTGGAA-CGCCAGCAT---TTTTTTTCAAATAAAATTTTTATTGCACCGTAGAGTGGTGCTTGTAA-CGCCAGCATCCTTTTTTTCATTTAAATTTTTTGTTGCACCT--GAATGGTGCTTGAAATG CGCCAGCATCCTTTTTTTCAAATAATTTTTTTGTTGCACCG--GATTGGTGCTTGGAA-CGCCAGCATCCTTTTTTTCAAATAATTTTTTTGTTGCACCG--GATTGGTGCTTGGAA-********** $* * * * * * * * * * * * * * * * * * * * * * \quad * \quad * * * * * * * * * * *$

Fig. 5. Alignment of ITS1 sequences for Hoplolaimus smokyensis n. sp. and the four closest Hoplolaimus species. Positions without an asterisk indicate polymorphisms, or differences between H. smokyensis $\mathrm{n}$. sp. and at least one of the other four species. 
$X . M a$ et al.

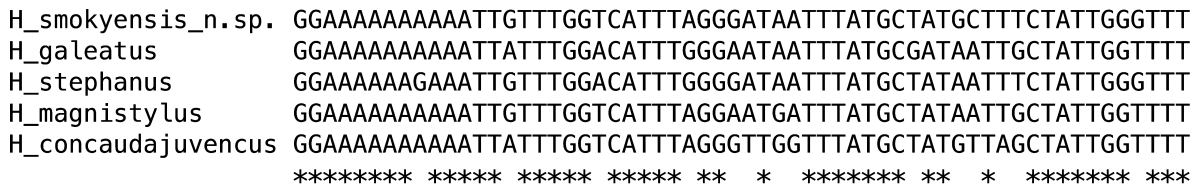

H_smokyensis_n.sp. ATTGGTTGTTTAGTTTGGGCTCATCATATATTTGTAGTTGGAATAGATTTAGATAGTCGA $\mathrm{H}$ galeatus ATTGGGTGTTTGGTTTGGGCCCATCATATGTTTGTGGTTGGGATGGATTTGGATAGCCGG H_stephanus ATTGGTTGTTTGGTTTGAGCTCATCATATGTTTGTTGTGGGAATAGATTTGGATAGGCGG H_magnistylus ATTGGTTGTTTAGTTTGAGCTCATCATATGTTTGTTGTAGGAATAGACTTGGATAGACGT H_concaudajuvencus ATTGGTTGTTTGGTTTGGGCTCATCATATATTTGTTGTTGGAATGGATTTAGATAGACGT ***** ****** ***** ** ******** ***** ** ** ** ** ** ***** **

H_smokyensis $n . s p$. GCTTATTTTAGTGCTGCTACAATGATTATCGCAGTACCTACTGGTATTAAAGTTTTTTCT H_galeatus GCTTATTTTAGGGCGGCTACTATAATTATTGCGGTTCCGACTGGGATTAAGGTTTTTTCC H_stephanus GCTTATTTTAGTGCAGCTTCTATAATTATTGCTGTTCCAACTGGTATTAAGGTTTTTTCT H_magnistylus GCTTATTTTAGGGCAGCAACGATGATTATTGCAGTTCCTACTGGTATTAAAGTTTTTTCT H_concaudajuvencus GCTTATTTTAGTGCTGCTACTATAATTATTGCTGTTCCTACTGGTATTAAGGTTTTTTCT $* * * * * * * * * * * * * * * \quad * * * * * * * * * * * * * * * * * * * * * * * * * * * * * * * * *$

H_smokyensis_n.sp. TGATTAATAACATTACATGCTTCTGTTTTATTTAATAGTTATTTATATGATTGGGTAATA H_galeatus TGGTTAATAACTTTGTTTTCTTCGATTTTTTTTTAACAGTTACCTTTTGGATTGGGTGATA H_stephanus TGGTTAATAACTTTATATTCTTCGGTTTTGTTTGATAGATTTTTTATTTGAATGAGTAATA H_magnistylus TGAATAATAACTTTATATGCTTCAGTTTTATTTAATAGTTATTTATATTATTGGGTTTTG H_concaudajuvencus TGATTGATGACTTTATATTCTTCAATTTTATTTACTAGTTATTTATTTGAATGGGTAATA ** $* * * * * * * \quad * * * * * \quad * * * * * * * \quad * * * \quad * * \quad * * * * * \quad *$

H_smokyensis_n.sp. GGTTTTATTTATTTATTTACTATAGGGGGTTTAAGAGGTTTAGTTTTAAGTAATGCTAGT H_galeatus GGTTTTATTTATTTGTTTACAATTGGGGGTTTAAGTGGTTTAATTTTGAGGAACGCAAGT H_stephanus GGTTTTGTTTATTTATTTACTTTAGGTGGTTTGACTGGTTTGGTTTTGAGTAATGCTAGT H magnistylus GGATTTATTTATTTGTTTACTTTGGGAGGTTTAAGTGGATTAATTTTAAGTAATGCTAGT H_concaudajuvencus GGTTTTATTTATTTGTTTACTTTTGGTGGTTTAAGAGGTTTAGTTTTGAGAAATGCAAGT ** *** ******* ***** $* * * * * * * * * \quad * *$ ** $* * * * * * * * * * * * *$

H_smokyensis_n.sp. TTGGATTTATTATTACATGATAC H_galeatus TTGGATTTGTTATTACATGACAC H_stephanus TTAGATTTATTGTTACATGATAC H_magnistylus TTAGATTTATTACTTCATGATAC H_concaudajuvencus TTGGATTTATTATTACATGATAC ********** *********

Fig. 6. Alignment of COI gene sequences for Hoplolaimus smokyensis n. sp. and the four closest Hoplolaimus species. Positions without an asterisk indicate polymorphisms, or differences between $H$. smokyensis n. sp. and at least one of the other four species.

bers KP230658, KP230659, KP303683 and KP303684. All specimen information and GenBank accession numbers of Hoplolaimus species used in this study are listed in Table 2 (ITS1 sequences) and Table 3 (COI sequences). Sequences were first aligned with BLAST in GenBank. The BLAST results suggested $H$. magnistylus as the closest species to $H$. smokyensis $n$. sp. with $89 \%$ identity (of both ITS 1 and COI sequences) when query cover is $100 \%$.

Sequences from all available lance nematode species with four lateral incisures were analysed. Alignments of ITS1 and COI sequences for H. smokyensis n. sp. and the four closest Hoplolaimus species are presented (Figs 5, 6). Positions without an asterisk indicate polymorphisms, or differences between $H$. smokyensis $\mathrm{n}$. sp. and at least one of the other four species. Phylogenetic analyses (Figs 7,8) based on the ribosomal and mitochondrial gene sequences suggest $H$. smokyensis n. sp. as a distinct lineage from $H$. galeatus, $H$. stephanus, $H$. magnistylus, and $H$. concaudajuvencus (Bayesian posterior probability $100 \%$ in ITS1 tree and $100 \%$ in $\mathrm{COI}$ tree) and separate from other $\mathrm{Ho}$ plolaimus spp. such as $H$. columbus. Compared with other reported species, the phylogenetic results also suggested: i) H. smokyensis n. sp. is classified into a unique clade; and $i$ ) in the ITS1 tree, H. smokyensis n. sp. is grouped with all other morphologically similar species in a large clade (four lateral incisures, three pharyngeal gland nuclei), and is separated from both $H$. columbus or H. seinhorsti, which have six pharyngeal gland nuclei and only a single lateral incisure. 


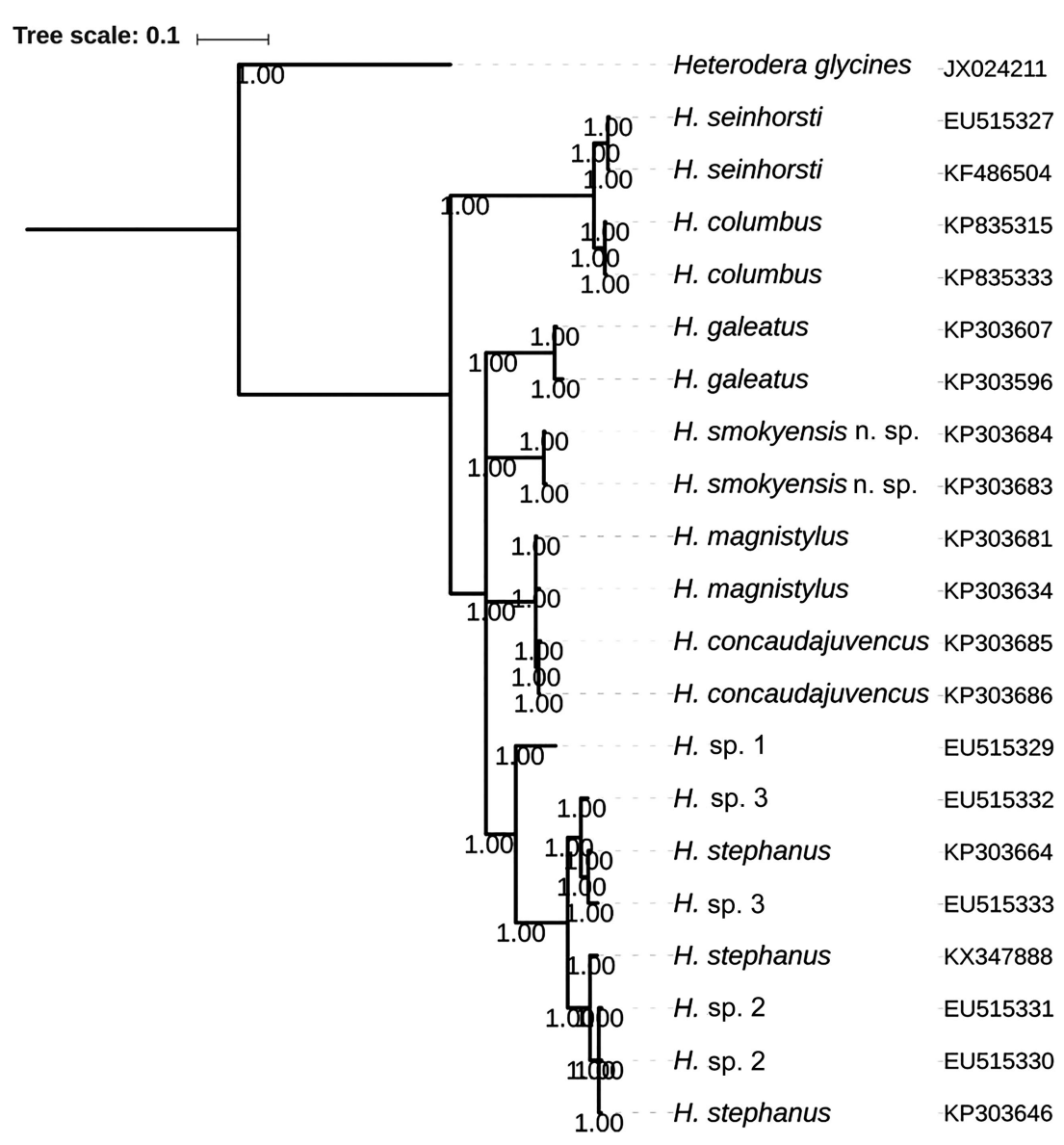

Fig. 7. Molecular phylogeny of Hoplolaimus species based on unique ITS1 DNA sequences. Heterodera glycines ITS1 sequence was included as an outgroup. Bayesian Inference tree obtained with MrBayes. Model: GTR $+\mathrm{I}+\mathrm{G}$. MCMC $=1 \times 10^{7}$ generations.

\section{Discussion}

Hoplolaimus species are found feeding on the roots of a diversity of monocotyledonous and dicotyledonous plants. The genus is widely distributed in the USA (Wrather et al., 1992; Martin et al., 1994; Gazaway \& McLean, 2003), and there are records from Canada, South America, Central America, and India on a variety of hosts (Fortuner, 1991). Based on differences in morphological characters, Siddiqi (2000) suggested dividing $\mathrm{Ho}$ plolaimus spp. into three subgenera according to lateral field incisures and the number of pharyngeal gland cell nuclei. With four incisures and three nuclei in the pharyngeal gland lobe, $H$. smokyensis $\mathrm{n}$. sp. belongs to the subgenus Hoplolaimus.

To date, seven Hoplolaimus spp. have been reported from the south-eastern USA, including $H$. columbus Sher, 1963, H. concaudajuvencus, H. galeatus, H. magnistylus,
H. stephanus, H. seinhorsti Luc, 1958, and H. tylenchiformis. Of these, H. columbus, H. galeatus, and H. magnistylus have been shown to be economically important and can cause serious damage to agronomic crops including cotton (Gossypium hirsutum), corn (Zea mays) and soybean (Glycine max) (Fassuliotis, 1974; Nyczepir \& Lewis, 1979; Robbins et al., 1987, 1989; Henn \& Dunn, 1989; Noe, 1993).

In this study we have described $H$. smokyensis n. sp. from a mixed forest sample of maple, hemlock, and silverbell tree in Great Smoky Mountains National Park. Pathogenicity of $H$. smokyensis n. sp. has not been reported from any agricultural field yet, although its similarity to $H$. galeatus may have caused it to be overlooked in agricultural nematode surveys. Several lance nematode species, $H$. stephanus, $H$. magnistylus and $H$. concaudajuvencus, which have been reported to infect trees, are known to also feed on crops such as corn, cotton, soybean, 


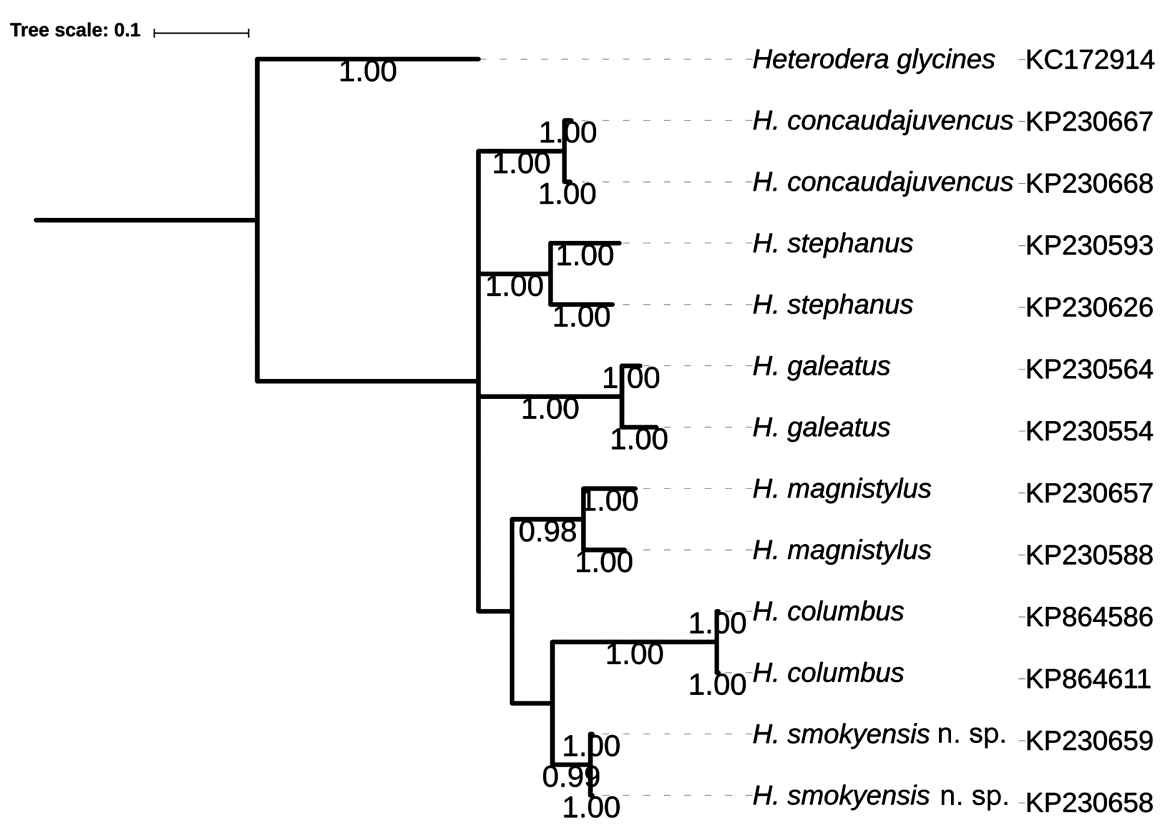

Fig. 8. Molecular phylogeny of Hoplolaimus species based on unique sequences of COI gene DNA. Heterodera glycines COI sequence was included as an outgroup. Bayesian Inference tree obtained with MrBayes. Model: GTR $+\mathrm{I}+\mathrm{G}$. MCMC $=1 \times 10^{7}$ generations.

and turfgrass (Ma et al., 2011, Holguin et al., 2015b). Hoplolaimus galeatus is also a prevalent pathogen of turf grasses such as St Augustinegrass (Stenotaphrum secundatum) and bermudagrass (Cynodon dactylon) in Florida (Henn \& Dunn, 1989). These species are in subgenus Hoplolaimus with similar morphological characteristics to H. smokyensis $\mathrm{n}$. sp. Identification and description of this new species will contribute to studies of comparative biology and evolutionary biology of lance nematodes.

\section{Acknowledgement}

This research was supported by the South Carolina Soybean Board and the South Carolina Cotton Board.

\section{References}

Bae, C.H., Szalanski, A.L. \& Robbins, R.T. (2008). Molecular analysis of the lance nematode, Hoplolaimus spp., using the first internal transcribed spacer and the D1-D3 expansion segments of $28 \mathrm{~S}$ ribosomal DNA. Journal of Nematology 40 , 201-209.

Bae, C.H., Robbins, R.T. \& Szalanski, A.L. (2009). Molecular identification of some Hoplolaimus species from the USA based on duplex PCR, multiplex PCR and PCRRFLP analysis. Nematology 11, 471-480. DOI: 10.1163/ $156854109 \mathrm{X} 447042$
Cid Del Prado Vera, I. (1994). Tres nuevos miembros de Hoplolaiminae (Nemata: Hoplolaimidae) de Mexico. Nematropica 24, 123-131.

Cobb, N.A. (1913). New nematode genera found inhabiting fresh water and non-brackish soils. Journal of the Washington Academy of Sciences 3, 432-444. DOI: 10.5962/bhl.part. 20323

Derycke, S., Remerie, T., Vierstraete, A., Backeljau, T., Vanfleteren, J., Vincx, M. \& Moens, T. (2005). Mitochondrial DNA variation and cryptic speciation within the freeliving marine nematode Pellioditis marina. Marine Ecology Progress Series 300, 91-103. DOI: 10.3354/meps300091

Edgar, R.C. (2004). MUSCLE: multiple sequence alignment with high accuracy and high throughput. Nucleic Acids Research 32, 1792-1797. DOI: 10.1093/nar/gkh340

Fassuliotis, G. (1974). Host range of the Columbia lance nematode Hoplolaimus columbus. Plant Disease Reporter 58, 1000-1002.

Fortuner, R. (1974). Description de Pratylenchus sefaensis n. sp. et de Hoplolaimus clarissimus n. sp. (Nematoda: Tylenchida). Cahiers ORSTOM, Série Biologie 21(1973), 25-34.

Fortuner, R. (1991). The Hoplolaiminae. In: Nickle, W.R. (Ed.). Manual of agricultural nematology. New York, NY, USA, Marcel Dekker, Inc., pp. 669-719.

Gazaway, W.S. \& McLean, K.S. (2003). A survey of plant parasitic nematodes associated with cotton in Alabama. The Journal of Cotton Science 7, 1-7.

Golden, A.M. \& Minton, N.A. (1970). Description and larval heteromorphism of Hoplolaimus concaudajuvencus, n. sp. 
(Nematoda: Hoplolaimidae). Journal of Nematology 2, 161166.

Handoo, Z. \& Golden, A.M. (1992). A key and diagnostic compendium to the species of the genus Hoplolaimus Daday, 1905 (Nematoda: Hoplolaimidae). Journal of Nematology 24, 45-53.

Henn, R.A. \& Dunn, R.A. (1989). Reproduction of Hoplolaimus galeatus and growth of seven St. Augustinegrass (Stenotaphrum secundatum) cultivars. Nematropica 19, 81-87.

Holguin, C.M., Baeza, J.A., Mueller, J.D. \& Agudelo, P. (2015a). High genetic diversity and geographic subdivision of three lance nematode species (Hoplolaimus spp.) in the United States. Ecology and Evolution 5, 2929-2944. DOI: 10. 1002/ece3.1568

Holguin, C.M., Ma, X., Mueller, J.D. \& Agudelo, P. (2015b). Distribution of Hoplolaimus species in soybean fields in South Carolina and North Carolina. Plant Disease 99, 1-5. DOI: 10.1094/PDIS-12-14-1332-RE

Huelsenbeck, J.P. \& Ronquist, F. (2001). MrBayes: Bayesian inference of phylogenetic trees. Bioinformatics 17, 17541755. DOI: 10.1093/bioinformatics/17.8.754

Jenkins, W.R. (1964). A rapid centrifugal-flotation technique for separating nematodes from soil. Plant Disease Reporter 48, 692.

Larget, B. \& Simon, D.L. (1999). Markov chain Monte Carlo algorithms for the Bayesian analysis of phylogenetic trees. Molecular Biology and Evolution 16, 750-759. DOI: 10.1093/ oxfordjournals.molbev.a026160

Letunic, I. \& Bork, P. (2016). Interactive tree of life (iTOL) v3: an online tool for the display and annotation of phylogenetic and other trees. Nucleic Acids Research 44, 242-245. DOI: 10.1093/nar/gkw290

Luc, M. (1981). Basirolaimus Shamsi, 1979, a junior synonym of Hoplolaimus von Daday, 1905 (Nematoda: Tylenchida). Nematologia Mediterranea 9, 197-199.

Ma, X., Agudelo, P., Mueler, J.D. \& Knap, H.T. (2011). Molecular characterization and phylogenetic analysis of Hoplolaimus stephanus. Journal of Nematology 43, 25-34.

Martin, S.B., Mueller, J.D., Saunders, J.A. \& Jones, W.I. (1994). A survey of South Carolina cotton fields for plant-parasitic nematodes. Plant Disease 78, 717-719. DOI: 10.1094/PD78-0717

Noe, J.P. (1993). Damage functions and population changes of Hoplolaimus columbus on cotton and soybean. Journal of Nematology 25, 440-445.

Nyczepir, A.P. \& Lewis, S.A. (1979). Relative tolerance of selected soybean cultivars to Hoplolaimus columbus and possible effects of soil temperature. Journal of Nematology 11, 27-31.

Posada, D. \& Crandall, K. (1998). MODELTEST: testing the model of DNA substitution. Bioinformatics 14, 817-818. DOI: 10.1093/bioinformatics/14.9.817

Robbins, R.T. (1982). Description of Hoplolaimus magnistylus n. sp. (Nematoda: Hoplolaimidae). Journal of Nematology 14, 500-506.

Robbins, R.T., Riggs, R.D. \& Von Steen, D. (1987). Results of annual phytoparasitic nematode surveys of Arkansas soybean fields, 1978-1986. Annals of Applied Nematology 1, 50-55.

Robbins, R.T., Riggs, R.D. \& Von Steen, D. (1989). Phytoparasitic nematode survey of Arkansas cotton fields, 1986-1988. Supplement to the Journal of Nematology 21, 619-623.

Robinson, O., Dylus, D. \& Deesimoz, C. (2016). Phylo.io: interactive viewing and comparison of large phylogenetic trees on the web. Molecular Biology and Evolution 33, 21632166. DOI: $10.1093 / \mathrm{molbev} / \mathrm{msw} 080$

Shamsi, M.A. (1979). Basirolaimus gen. n. (Nematoda: Hoplolaimidae) with the description of Basirolaimus sacchari n. sp. from India. Nematologia Mediterranea 7, 15-19.

Sher, S.A. (1963). Revision of the Hoplolaiminae (Nematoda) II. Hoplolaimus Daday, 1905 and Aorolaimus n. gen. Nematologica 9, 267-296. DOI: 10.1163/187529263X00476

Siddiqi, M.R. (1972). Two new species of Scutellonema from cultivated soils in Africa with a description of Hoplolaimus aorolaimoides sp. n. from Portugal (Nematoda: Hoplolaiminae). Proceedings of the Helminthological Society of Washington 39, 7-13.

Siddiqi, M.R. (2000). Tylenchida parasites of plants and insects, 2nd edition. Wallingford, UK, CABI Publishing. DOI: 10. 1079/9780851992020.0000

Thorne, G. (1935). Notes on free-living and plant-parasitic nematodes, 2. Proceedings of the Helminthological Society of Washington 2, 96-98.

von Daday, E. (1905). Untersuchungen über die SüsserwasserMikrofauna Paraguays. Zoologica, Stuttgart 18, 1-349.

Wrather, J.A., Niblack, T.L. \& Milam, M.R. (1992). Suvey of plant-parasitic nematodes in Missouri cotton fields. Journal of Nematology 24, 779-782.

Ye, W. \& Robbins, R.T. (2003). Longidorus grandis n. sp. and L. paralongicaudatus n. sp. (Nematoda: Longidoridae), two parthenogenetic species from Arkansas. Journal of Nemato$\log y 35,375-387$. 